\title{
Modifikasi IDFIFv2 Untuk Penanganan Smartwatch Forensic SDLC
}

\author{
Abdul Gani Lihawa \\ Magister Informatika, Fakultas \\ Teknologi Industri \\ Universitas Islam Indonesia \\ Yogyakarta, Indonesia \\ Vavanlihawa20@gmail.com
}

\author{
Yudi Prayudi \\ Magister Informatika, Fakultas \\ Teknologi Industri \\ Universitas Islam Indonesia \\ Yogyakarta, Indonesia \\ Prayudi@uii.ac.id
}

\author{
Erika Ramadhani \\ Magister Informatika, Fakultas \\ Teknologi Industri \\ Universitas Islam Indonesia \\ Yogyakarta, Indonesia \\ Erika@uii.ac.id
}

\begin{abstract}
This study aimed to specify the process of modifying the IDFIF v2 framework as a forensic smartwatch framework using the SDLC method and to specify the results of smartwatch acquisition and analysis after modifying IDFIF v2. The method used was the SDLC method that used to modify IDFIF $v 2$ and has 6 stages, namely planning, analysis, design, implementation, and maintenance. After obtaining the modified IDFIF v2 results, a case study was carried out using the Kingwear 88 smartwatch as the object of study and using the Mobiledit forensic tools as a forensic analysis tool. The results showed that in implementing the framework, at the completion of the smart watch investigation, there were no wasted or unused stages. this showed that IDFIF v2 is a flexible framework that can include forensic analysis of various kinds of devices, one of that is smartwatch. So that the completion of the forensic smartwatch can be carried out all steps taken for the forensic smartwatch analysis.
\end{abstract}

Keywords-IDFI v2; SDLC; smartwatch.

Abstrak-Penelitian ini bertujuan untuk mengetahui proses modifikasi framework IDFIFv2 sebagai kerangka kerja forensik smartwatch dengan menggunakan metode SDLC dan untuk mengetahui hasil akusisi dan analisis smartwatch setelah memodifikasi IDFIFv2. Metode yang digunakan adalah metode SDLC yang digunakan untuk melakukan modifikasi IDFIF v2 dan memiliki 6 tahapan yaitu planning, analysis, design, implementation, dan maintenance. Setelah mendapatkan hasil modifikasi IDFIF v2, studi kasus dilakukan dengan menggunakan smartwatch kingwear 88 sebagai objek penelitian dan menggunakan tools forensik Mobiledit sebagai tools analisis forensik. Hasil penelitian menunjukkan bahwa dalam penerapan framework, pada penyelesaian investigasi smartwatch tidak ditemukan adanya tahapan yang terbuang atau tidak terpakai, hal ini menunjukkan bahwa IDFIF v2 adalah salah satu framework yang fleksibel yang bisa mencakup analisa forensik berbagai macam device salah satunya adalah smartwatch. Sehingga dalam penyelesaian smartwatch forensik yang dilakukan dapat mencakup segala tahapan yang dilakukan untuk analisa smartwatch forensik.

Keywords-IDFIFv2; SDLC; smartwatch.

\section{PENDAHULUAN}

Dewasa ini, smartphone telah mengalami berbagai macam perubahan dan semakin berkembang seiring berjalannya waktu. Arti dari smartphone (telepon pintar) adalah telepon genggam yang mempunyai kemampuan tingkat tinggi dengan fungsi yang menyerupai komputer (Ii \& Teori, 2017). Kemudian terus berkembang hingga saat ini, dan yang paling banyak dikenal adalah penggunaan dua sistem operasi yaitu android dan ios; android dipelopori oleh
Google dan ios dipelopori oleh Apple. Semakin mudahnya pekerjaan, transaksi jual beli, dan komunikasi yang dimiliki oleh smartphone, semakin menarik minat masyarakat untuk membelinya. Bahkan saat ini sudah ada teknologi jam tangan yang dinamakan smartwatch atau jam tangan pintar. Smartwatch merupakan salah satu aksesoris yang sering digunakan karena keunggulannya yang bisa melakukan konektivitas ke smartphone, sehingga dengan memakai smartwatch, pengguna dapat mengetahui notifikasi, melihat foto, melihat agenda, bahkan mengatur pola tidur pengguna.

Dengan adanya kemajuan teknologi, hadirlah hal positif dan negatif di kalangan masyarakat; ada masyarakat yang menggunakan teknologi untuk hal-hal yang bermanfaat, dan ada pula masyarakat yang menggunakannya untuk hal-hal yang bertentangan dengan hukum. Berkaitan dengan hal tersebut, disahkanlah Pasal 5 ayat (1) UU ITE: Informasi Elektronik dan/atau Dokumen Elektronik dan/atau hasil cetaknya merupakan alat bukti hukum yang sah. Dengan kata lain, smartwatch dapat menjadi salah satu bukti elektronik yang sah. Pasal tersebut menyatakan bahwa seluruh informasi maupun barang bukti elektronik bisa dijadikan sebagai barang bukti. Dengan demikian, smartwatch termasuk salah satu alat bukti jika digunakan untuk melakukan suatu tindak pidana.

Dalam sebuah kasus, metode maupun kerangka kerja yang digunakan harus dapat menaungi sebuah investigasi. Demikian juga dengan kerangka kerja dalam forensika digital. Setiap penanganan kasus memiliki kerangka kerja yang berbeda-beda, tergantung bukti elektronik ataupun bukti digital yang dikerjakan. Kerangka kerja dimaksudkan agar investigasi kasus lebih terarah dan memiliki proses yang dapat dipertanggungjawabkan. Hingga kini, dalam hal penanganan smartwatch, kerangka kerja yang ada belum bisa memaksimalkan forensik smartwatch. Berangkat dari hal tersebut, penelitian ini bertujuan untuk memodifikasi framework atau kerangka kerja IDFIF v2 (Integrated Digital Forensic Investigation Framework) IDFIF v2. Sebelumnya, telah ada IDFIF v1, tetapi versi tersebut tidak digunakan untuk penerapan dalam penelitian ini dikarenakan IDFIF v1 masih dikhususkan untuk perangkat komputer. Kemudian, versi tersebut diperbaiki dan disempurnakan menjadi IDFIF v2, dan dijadikan salah satu patokan dalam analisis forensik tentang smartwatch yang terhubung dengan smartphone yang bisa menjadi sebuah alat bukti dalam sebuah kejahatan. Pada penelitian-penelitian terdahulu, IDFIFv2 hanya diterapkan pada smartphone. Terlebih, metode penelitian yang 
digunakan pada penelitian ini juga berbeda dengan metode penelitian yang digunakan pada penelitian sebelumnya, dimana penelitian ini menggunakan metode SDLC. Sehingga penelitian ini penerapan idv2 terhadap bukti elektronik smartwatch. Diharapkan sebagai acuan dalam proses investigasi kasus forensic smartwatch.

Selain itu, proses analisis penelitian ini juga menggunakan metode System Development Life Cycle (SDLC).

System Development Life Cycle (SDLC) merupakan sebuah proses pembuatan dan pengubahan sistem serta model dan metodologi yang digunakan untuk mengembangkan sebuah sistem. Menurut Rhodes (2012), SDLC memiliki 5 tahapan yaitu planning, analysis, design, implementation, dan maintenance. SDLC termasuk salah satu metode yang bisa digunakan untuk pembangunan maupun pengembangan sebuah framework. Karena pada dasarnya, setiap pengembangan maupun pembuatan framework harus memiliki tahapan agar proses yang terjadi bisa lebih maksimal dan lebih terstruktur. Sehingga dengan metode ini, penerapan modifikasi IDFIF v2 bisa diimplementasikan dan juga bisa terstruktur dengan baik.

\section{IDFIFv2}

Pada penerapan IDFIFv2 yang dilakukan oleh (Ruuhwan, Riadi, \& Prayudi, 2016). Jurnal ini membahas tentang analisis forensic terhadap smartphone dengan menggunakan IDFIF v2 sebagai acuan dalam penyelesaian kasus smartphone forensic. Hasil penerapannya bisa diterapkan sebagai acuan dalam analisis kasus smartphone di jurnal ini juga dibuatnya IDFIF v2 yang sebelumnya IDFIF kemudian distrukturisasi kembali.

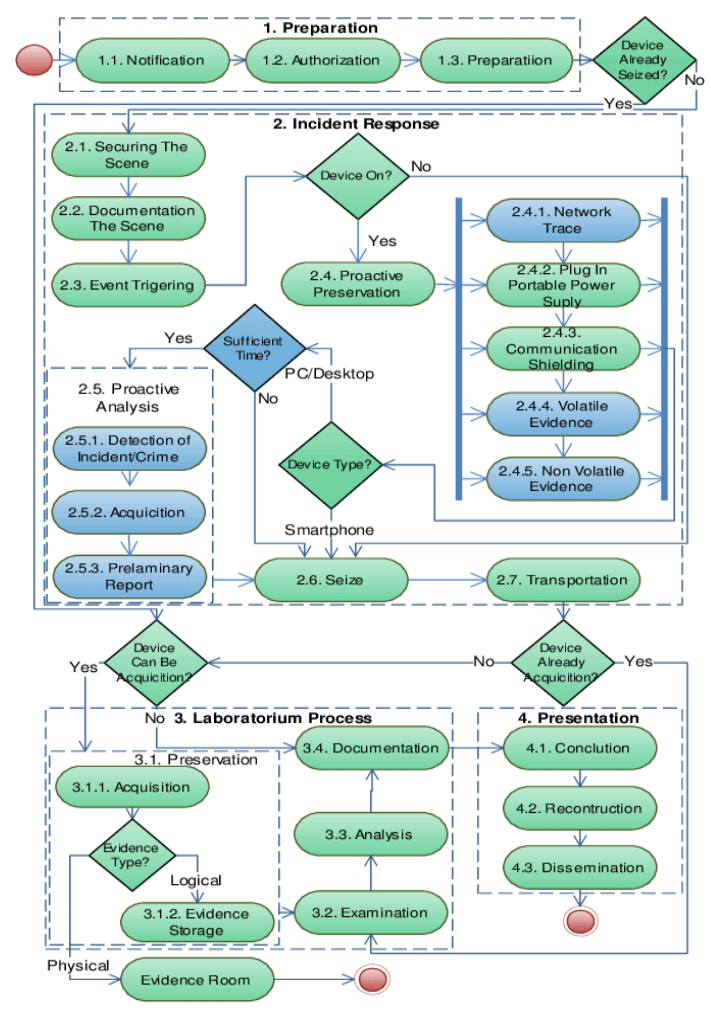

Gambar 1. IDFIF v2
Smartwatch atau jam tangan pintar merupakan salah satu kemajuan teknologi. Semua smartwatch pada dasarnya memiliki kerja sebagai aksesoris dari smartphone yang memiliki kemampuan bermacam-macam dan juga sekaligus merupakan salah satu alat elektronik yang bisa dijadikan alat bukti dalam sebuah kasus. Berkaitan dengan hal tersebut, analisis forensik terhadap jam tangan pintar dan menggunakan aplikasi forensik di antara lain Mobiledit dan Metasploit (Putra et al., 2017) Sedangkan pada penelitian lainnya, (Baggili et al., 2015) melakukan identifikasi terhadap bukti forensik yang dapat diperoleh dari jam tangan pintar atau sebagai hasil dari data yang dikumpulkan oleh perangkat ini yang disimpan di ponsel pintar yang terhubung dengan jam tangan pintar tersebut.

Kemudian pada jurnal oleh (Odom, Lindmar, Hirt, \& Brunty, 2019) membahas tentang pemahaman yang ditingkatkan smartwatch sebagai perangkat yang dapat dipakai dengan kemampuan jaringan seluler berinteraksi dengan ponsel dan di mana data pengguna yang sensitif berupa artefak data tersebut disimpan. Jurnal ini menggunakan framework NIST.

\section{METODE PENELITIAN}

Untuk menyelesaikan penelitian ini, dibutuhkan tahapantahapan penyelesaian penelitian. Berikut gambaran metode penelitian yang diimplelentasikan dalam penelitian ini

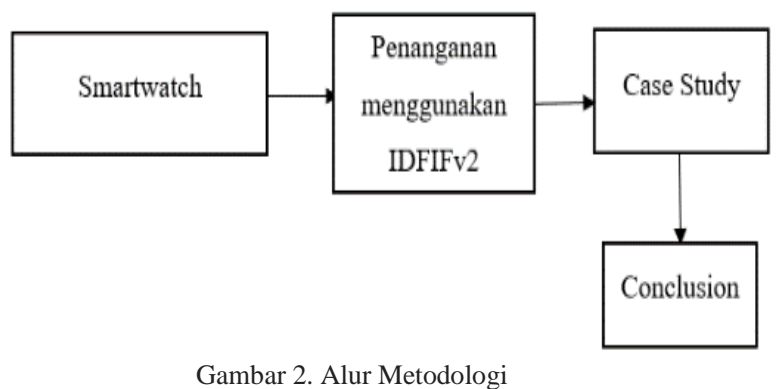

Tahapan pertama dalam penelitian ini adalah tahapan pengumpulan bahan informasi mengenai topik yang terkait dengan penelitian ini. Data penelitian ini bersumber dari artikel, paper, jurnal dan laporan penelitian terdahulu yang sebelumnya telah dilakukan. Juga meninjau website website yang membahas tentang forensik beserta smartwatch untuk mendukung penelitian ini.

Selanjutnya, tahapan kedua adalah tahapan yang menggunakan SDLC untuk memodifikasi IDFIF v2 agar dapat dijadikan sebagai framework dalam penanganan smartwatch, SDLC sendiri memiliki tahapan yaitu: planning, analysis, design, implementation, dan maintenance.

Tahapan ketiga adalah studi kasus. Tahapan ini merupakan tahapan penerapan IDFIF v2 setelah dimodifikasi ke dalam smartwatch.

Tahapan terakhir atau keempat adalah kesimpulan yang membahas secara ringkas hasil dari penelitian ini.

\section{HASIL DAN PEMBAHASAN}

Berdasarkan metode pengembangan SDLC, didapatkan tabel yang membahas uraian penerapan model dan output. SDLC sendiri memiliki 5 tahapan yaitu planning, Analysis, Design, Implementation, Maintenance dari 5 tahapan ini 
diharapkan struktur kerja dari modifikasi IDFIF v2 ini dapat berjalan sesuai tahapan.

A. System Development Life Cycle (SDLC)

1) Planning

Tahapan awal ini membahas tentang tinjauan pustaka yang berhubungan dengan smartwatch forensic yang

Tabel 1. Tahapan dan teknik-teknik

\begin{tabular}{|c|c|c|c|}
\hline $\begin{array}{c}\text { No } \\
\text { Penelitian }\end{array}$ & Peneliti & Jenis Penelitian & Tahapan dan Teknik - teknik \\
\hline 1 & (Baggili et al., 2015) & Smartwatch Forensic & $\begin{array}{l}\text { 1.Methodology Use NIST (National institute of standard and } \\
\text { techonology) } \\
\text { 2. apparatus, deskripsi tools dan fungsi yang akan di gunakan } \\
\text { 3. scenario dan dokumentasi membuat suatu kasus dan di investigasi } \\
\text { pada smartwatch sekaligus menganalisa awal kejadian } \\
\text { 4. Proses Akuisisi Untuk melihat hashing atau originalitas file } \\
\text { 5. analisis menggunakan celebrite analyzier } \\
\text { 6. hasil ekstrakksi analisis }\end{array}$ \\
\hline 2 & (Putra et al., 2017) & Smartwatch forensic & $\begin{array}{l}\text { 1.pencarian informasi pada smartwatch yamg akan di forensik } \\
\text { 2.melakukan persiapan akan alat yang akan di forensik } \\
\text { 3. melakukan cloning terhadap smartwatch } \\
\text { 4. pengambilan data dan analisis } \\
\text { 5. menampilkan data dengan laporan }\end{array}$ \\
\hline 3 & (Odom et al., 2019) & Smartwatch Forensic & $\begin{array}{l}\text { 1. apparatus, deskripsi tools dan alat yang di gunakan. } \\
\text { 2. experimental setup, melakukan eksperimen berdasarkan alat yang } \\
\text { akan di forensik } \\
\text { 3. melakukan akuisisi data dengan menggunakan alur NIST } \\
\text { 4. hasil dari analisis dan akuisisi di jabarkan dengan rinci }\end{array}$ \\
\hline
\end{tabular}

\section{2) Analysis}

Tahapan selanjutnya adalah analisis terhadap tahapan dan teknik yang di gunakan pada penelitian sebelumnya. Analisis lebih lanjut dengan memetakan tahapan IDFIFv2 berdasarkan tahapan dan teknik pada penelitian terkait sebelumnya. Berdasarkan tahapan IDFIFv2 terdapat 4 tahapan dengan 16 sub tahapan yang sebelumnya di gunakan untuk penanganan forensik. Kerangka kerja IDFIFv2 ini memiliki 4 tahapan utama yaitu preparation, inciden response, laboratorium process, dan presentation yang dijabarkan berdasarkan tahapan dan teknik-teknik yang digunakan. Berikut tabel tahapan dan teknik yang digunakan oleh penelitian sebelumnya.

4. hasil dari analisis dan akuisisi di jabarkan dengan rinci

Tabel 2. Tahapan IDFIF v2 dan Penelitian Terkait

\begin{tabular}{|c|c|c|c|c|}
\hline \multicolumn{2}{|c|}{ IDFIFv2 } & Penelitian Terkait $_{1}$ & Penelitian Terkait $_{2}$ & ${\text { Penelitian } \text { Terkait }_{3}}$ \\
\hline \multirow[t]{3}{*}{ Preparation } & Notification & - & - & - \\
\hline & Authorization & - & - & - \\
\hline & Preparation & $\begin{array}{c}\text { Apparatus, deskripsi tools yang } \\
\text { akan digunakan }\left(\text { Tahapan }_{2}\right)\end{array}$ & $\begin{array}{l}\text { Identifikasi Data apa saja yang } \\
\left.\text { akan di forensik( } \text { (ahapan }_{1}\right) \\
\text { Pencarian Informasi File yang } \\
\text { akan di forensik seperti apa } \\
\text { (tahapan } 2) \\
\text { Persiapan alat untuk forensik } \\
\text { (Tahapan } 3)\end{array}$ & $\begin{array}{c}\text { Apparatus, } \\
\text { deskripsi tools } \\
\text { yang akan } \\
\text { digunakan }\end{array}$ \\
\hline \multirow[t]{6}{*}{ Inciden Response } & Securing The scene & Adegan Scenario(Tahapan 3 ) & - & - \\
\hline & Documentation The Scene & Documetasi Skenario $\left(\right.$ Tahapan $\left._{3}\right)$ & - & - \\
\hline & Event Trigering & Pemicu Kejadian $\left(\right.$ Tahapan $\left._{3}\right)$ & - & - \\
\hline & Proactive Preservation & - & - & - \\
\hline & Proactive Analysis & $\begin{array}{c}\text { Analisis Awal forensic atau } \\
\left.\text { hipotesa( } \text { Tahapan }_{3}\right)\end{array}$ & - & $\begin{array}{c}\text { Eksperimen } \\
\text { forensik awal } \\
\left(\text { Tahapan }_{2}\right)\end{array}$ \\
\hline & Seize & - & - & - \\
\hline
\end{tabular}

masing-masing tahapannya akan di petakan ke dalam sebuah tabel yang isinya adalah tahapan IDFIFv2 dan tahapan penelitian terkait sebelumnya. Kemudian setiap tahapan yang sesuai dengan tahapan pada penelitian sebelumnya akan di tempatkan sesuai dnegan tahapan pada IDFIFv2. Sehingga bisa di lihat pada kerangka kerja IDFIFv2 tahapan mana saja yang tidak mencakup tahapan dari penelitian sebelumnya. Berikut tabel perbandingan IDFIFv2 dan penelitian terkait. 
Jurnal Teknologi Informasi dan Terapan (J-TIT) Vol. 8 No. 1 Juni 2020 ISSN: 2580-2291

\begin{tabular}{|c|c|c|c|c|}
\hline \multicolumn{2}{|c|}{ IDFIFv2 } & Penelitian Terkait $_{1}$ & Penelitian Terkait $_{2}$ & Penelitian Terkait $_{3}$ \\
\hline \multirow[t]{4}{*}{ Preparation } & Notification & - & - & - \\
\hline & Authorization & - & - & - \\
\hline & Preparation & $\begin{array}{l}\text { Apparatus, deskripsi tools yang } \\
\text { akan digunakan }\left(\text { Tahapan }_{2}\right)\end{array}$ & 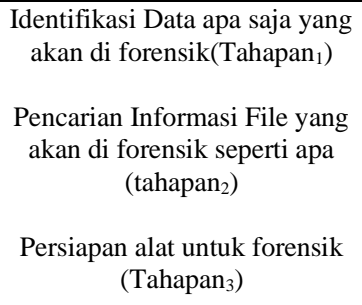 & $\begin{array}{c}\text { Apparatus, } \\
\text { deskripsi tools } \\
\text { yang akan } \\
\text { digunakan }\end{array}$ \\
\hline & Transportation & - & - & - \\
\hline \multirow[t]{4}{*}{$\begin{array}{l}\text { Laboratorium } \\
\text { Process }\end{array}$} & Preservation & $\begin{array}{l}\text { Hashing untuk memastikan } \\
\text { originalitas file ( } \text { tahapan }_{4} \text { ) }\end{array}$ & Akuisisi Data $\left(\right.$ Tahapan $\left._{4}\right)$ & $\begin{array}{l}\text { Akuisisi untuk } \\
\text { Hashing dan } \\
\text { memastikan } \\
\text { originalitas file } \\
\left(\text { Tahapan }_{3}\right)\end{array}$ \\
\hline & \multicolumn{4}{|c|}{$v$} \\
\hline & Examination & $\begin{array}{l}\text { Analisis Lebih lanjut dengan } \\
\text { aplikasi forensik }\left(\text { Tahapan }_{5}\right)\end{array}$ & $\begin{array}{l}\text { Pengambilan data dan analisis } \\
\qquad\left(\text { Tahapan }_{4}\right)\end{array}$ & $\begin{array}{c}\text { Analisis } \\
\text { berdasarkan hasil } \\
\text { akuisisi }\left(\text { Tahapan }_{3}\right)\end{array}$ \\
\hline & Documentation & - & - & - \\
\hline \multirow[t]{3}{*}{ Presentation } & Conclution & $\begin{array}{l}\text { Hasil ekstraksi analisis forensik } \\
\left.\text { (Tahapan }_{6}\right)\end{array}$ & $\begin{array}{l}\text { Tampilan data hasil } \\
\text { akuisisi(Tahapan }_{5} \text { ) }\end{array}$ & $\begin{array}{l}\text { Hasil Analisis } \\
\left(\text { Tahapan }_{4}\right)\end{array}$ \\
\hline & Recontruction & $\begin{array}{l}\text { Proses evaluasi analisis forensik } \\
\left.\qquad \text { (Tahapan }_{6}\right)\end{array}$ & & 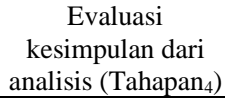 \\
\hline & Dissemination & - & - & - \\
\hline
\end{tabular}

Berdasarkan tahapan diatas kita dapat melihat kesesuaian IDFIF v2 dalam penanganan smartwatch dengan melakukan perbandingan berdasarkan penelitian sebelumnya tentang Analisis forensik smartwatch. Dan semua tahapan IDFIFv2 dapat mencakup kesesuaian dengan penelitian sebelumnya. Selanjutnya adalah pemetaan tahapan IDFIFv2 untuk smartwatch dalam hal ini penjabaran secara lengkap beserta keterangan untuk smartwatch. Sehingga bisa di identifikasi setiap tahapan untuk penggunaan IDFIFv2 terhadap smartwatch. Dimaksudkan untuk melihat setiap tahapan dalam penanganan smartwatch, dan bisa dijelaskan lebih lanjut sehingga setiap tahapan dapat disinkronkan dalam analisis investigasi smartwatch. Penerapan IDFIFv2 dan penelitian terkait sebelumnya akan di petakan dalam bentuk tabel.Berikut tabel penanganan smartwatch dengan IDIFIFv2.

Tabel 3. Penanganan Smartwatch Pada IDFIFv2

\begin{tabular}{|c|c|c|c|c|c|}
\hline No & \multicolumn{3}{|c|}{ IDIFIFv2 } & $\begin{array}{l}\text { Penanganan } \\
\text { smartwatch } \\
\text { forensik }\end{array}$ & Keterangan untuk smartwatch \\
\hline \multirow[t]{3}{*}{1} & \multirow[t]{3}{*}{ Preparation } & \multicolumn{2}{|c|}{ 1.1. Notification } & $\checkmark$ & \multirow{3}{*}{$\begin{array}{l}\text { Persiapan Lebih lanjut tentang tools dan alat yang di perlukan dalam } \\
\text { penanganan smartwatch lebih lanjut. Tidak ada perubahan signifikan } \\
\text { karena penanganan pada saat persiapan forensik sama. }\end{array}$} \\
\hline & & \multicolumn{2}{|c|}{ 1.2. Authorization } & $\checkmark$ & \\
\hline & & \multicolumn{2}{|c|}{ 1.3. Preparation } & $\checkmark$ & \\
\hline \multirow[t]{6}{*}{2} & \multirow{6}{*}{$\begin{array}{l}\text { Incident } \\
\text { Response }\end{array}$} & \multicolumn{2}{|c|}{ 2.1. Securing The Scene } & $\checkmark$ & \multirow{4}{*}{$\begin{array}{l}\text { Pencatatan kejadian di tkp secara lanjut di dokumentasikan secara } \\
\text { lengkap dengan. Rincian olah tkp terhadap barang bukti }\end{array}$} \\
\hline & & \multicolumn{2}{|c|}{$\begin{array}{l}\text { 2.2. Documentation The } \\
\text { Scene }\end{array}$} & $\checkmark$ & \\
\hline & & \multicolumn{2}{|c|}{ 2.3. Event Trigering } & $\checkmark$ & \\
\hline & & \multicolumn{2}{|c|}{ 2.4. Proactive Preservation } & $\checkmark$ & \\
\hline & & 2.4.1. & Network Trace & $\checkmark$ & $\begin{array}{l}\text { Dalam smartwatch untuk pencarian jejak belum bisa di katakan bisa } \\
\text { karena pada dasarnya smartwatch yang di teliti masih menggunakan } \\
\text { koneksi Bluetooth sehingga belum bisa di lakukan pelacakan secara } \\
\text { langsung }\end{array}$ \\
\hline & & 2.4 .2 & $\begin{array}{l}\text { Plug in Protable } \\
\text { Power Supply }\end{array}$ & $\checkmark$ & $\begin{array}{l}\text { Smartwatch termasuk barang elektronik yang membutuhkan baterai } \\
\text { ketika penggunaannya jadi sesuai }\end{array}$ \\
\hline
\end{tabular}


Jurnal Teknologi Informasi dan Terapan (J-TIT) Vol. 8 No. 1 Juni 2020 ISSN: 2580-2291

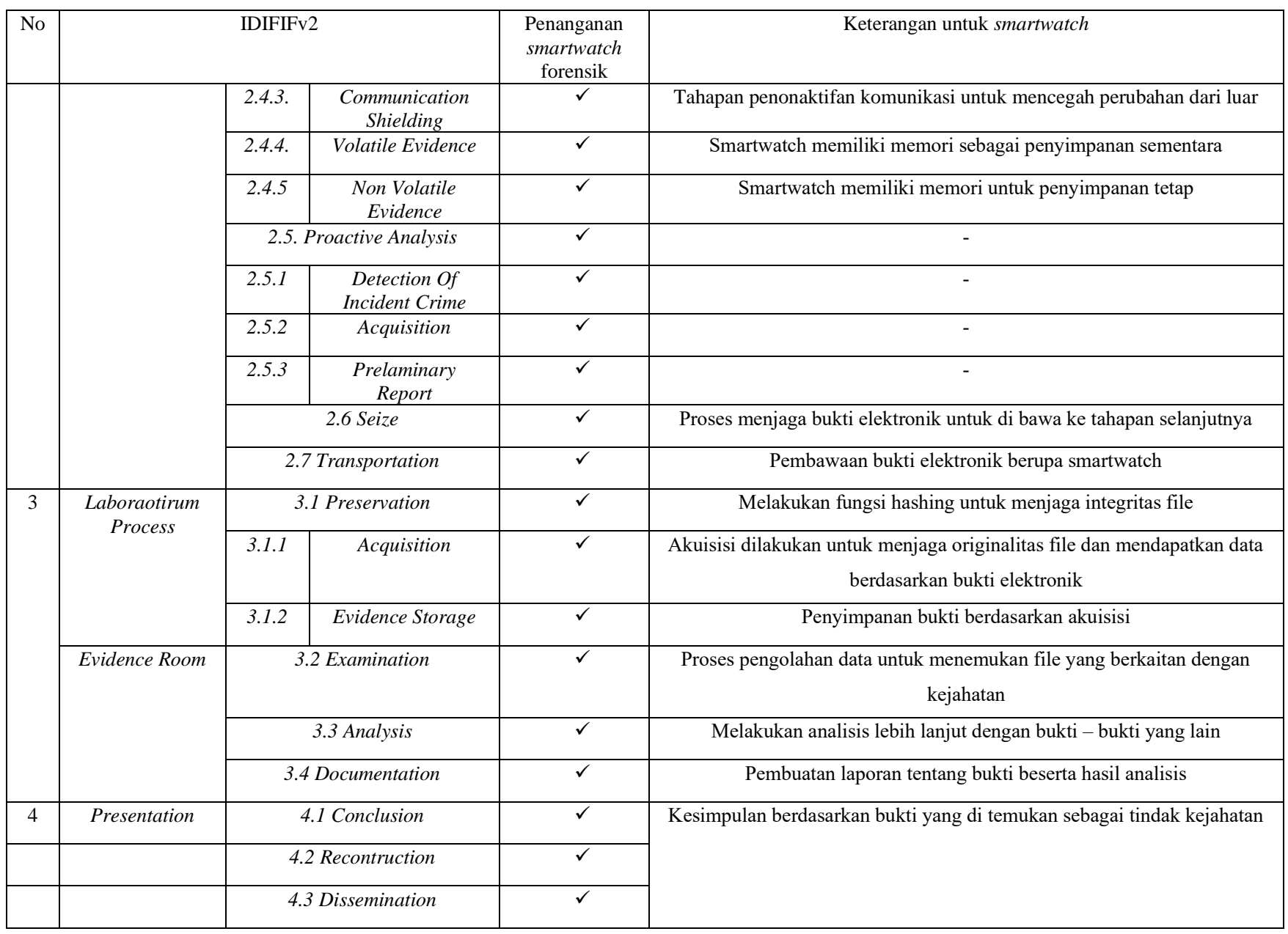

Berdasarkan tabel di atas, dapat disimpulkan bahwa IDFIF v2 adalah salah satu framework yang fleksibel untuk penanganan barang bukti digital hanya saja disini penulis mendapatkan bahwa apabila dengan framework yang sekompleks ini seharusnya bisa melakukan Analisa untuk forensik untuk skala yang lebih luas. Sehingga disini hasil analisis berdasarkan tabel smartwatch mumpuni untuk menggunakan IDFIFv2. Hanya saja pada IDFIFv2 pada tahapan device hanya tertulis smartphone, jadi disini akan dimodifikasi dengan kata "smartphone dan wearable devices" mengingat devices yang terhubung dengan smartphone kita bisa dijadikan bukti.

Berdasarkan hal tersebut, dapat disimpulkan bahwa IDFIF v2 sudah bagus untuk analisis forensik smartwatch tinggal modifikasi pada bagian devices sehingga bisa menjangkau Analisa forensik selain smartphone dalam hal ini smartwatch.

\section{3) Design}

Berdasarkan tahapan sebelumnya yaitu analysis framework IDFIFv2 ini sudah mencakup kerangka kerja yang cocok untuk penanganan smartwatch forensik bisa dilihat pada tabel 3 pada analisis bahwa IDFIFv2 sesuai untuk proses investigasi smartwatch, sehingga modifikasi yang dilakukan secara signifikan tidak ada selain memperluas jangkauan devices dari IDFIFv2 sehingga bisa mencakup berbagai macam wearable devices yang lain seperti smartwatch. Berikut gambar 3. menunjukan devices dalam IDFIFv2.

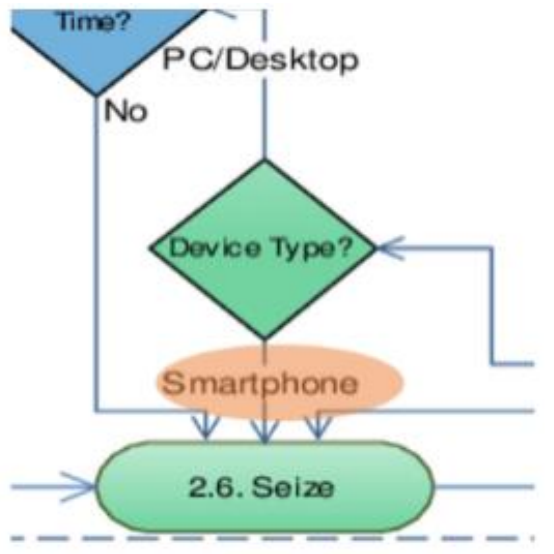

Gambar 3. Device Type IDFIFv2

Gambar di atas menunjukan devices yang bisa di lakukan oleh IDFIFv2 hanya PC dan smartphone sehingga kita bisa modifikasi dan memperluas jangkauan dengan menambahkan kata smartphone and wearable device, wearable device adalah sensor dan alat yang menempel di tubuh dimana pengunaannya mengacu pada teknologi elektronik atau komputer yang digabungkan di dalam pakaian dan nyaman dipakai. Berikut tabel 4 yang memperlihatkan tahapan IDFIF sebelum dan sesudah modifikasi. 
Jurnal Teknologi Informasi dan Terapan (J-TIT) Vol. 8 No. 1 Juni 2020 ISSN: 2580-2291

\begin{tabular}{|c|c|c|c|}
\multicolumn{5}{|c}{ Tabel 4. Modifikasi } \\
\hline NO & Tahapan IDFIFv2 & $\begin{array}{l}\text { Sebelum di } \\
\text { modifikasi }\end{array}$ & Modifikasi \\
\hline 1 & Device Type & Smartphone & $\begin{array}{c}\text { Smartphone \& } \\
\text { wearable devices }\end{array}$ \\
\hline
\end{tabular}

\begin{tabular}{|c|c|l|l|}
\hline NO & Tahapan IDFIFv2 & Modifikasi & $\begin{array}{l}\text { Perbedaan } \\
\text { setelah di } \\
\text { modifikasi }\end{array}$ \\
\hline 1 & $\begin{array}{c}\text { Decision devices type } \\
\text { (PC Desktop, } \\
\text { Smartphone) }\end{array}$ & $\begin{array}{l}\text { Devices Type } \\
\text { (PC Desktop, } \\
\text { Smartphone and } \\
\text { wearable } \\
\text { devices })\end{array}$ & $\begin{array}{l}\text { Jangkauan } \\
\text { kerangka kerja } \\
\text { jadi meluas, } \\
\text { tidak terbatas } \\
\text { pada } \\
\text { smartphone } \\
\text { dan pc desktop }\end{array}$ \\
\hline
\end{tabular}

Dalam hal ini tahapan penentuan devices type merupakan tahapan decision atau keputusan sehingga bisa menentukan langkah selanjutnya berdasarkan devices yang ditemukan di suatu kasus. Selanjutnya berikut tabel perbandingan tahapan framework sebelumnya dan sesudah di modifikasi.

Tabel 5. Perbedaan Setelah Modifikasi

\section{4) Implementation}

ini adalah tahapan penerapan hasil dari desain sebelumnya dan diterapkan dalam modifikasi IDFIFv2. Sehingga dalam tahapan ini bisa dilihat secara signifikan desain yang baru. Berdasarkan tahapan sebelumnya bahwa tidak terdapat eliminasi dari tahapan kerangka kerja IDFIF

Demikian tabel di atas membahas tentang perbedaan setelah modifikasi, pada tahapan design ini sendiri mengkhususkan desain kembali framework berdasarkan analysis sebelumnya, dan dengan mendapatkan hasil modifikasi kemudian dilanjutkan ke tahapan selanjutnya.

v2. Yang ada adalah modifikasi devices type dari IDFIFv2 yang sebelumnya smartphone kemudian diubah menjadi "Smartphone \& Wearable Devices" sehingga jangkauan penggunaan kerangka kerja ini jadi lebih meluas. Berikut kerangka kerja IDFIFv2 setelah di modifikasi.

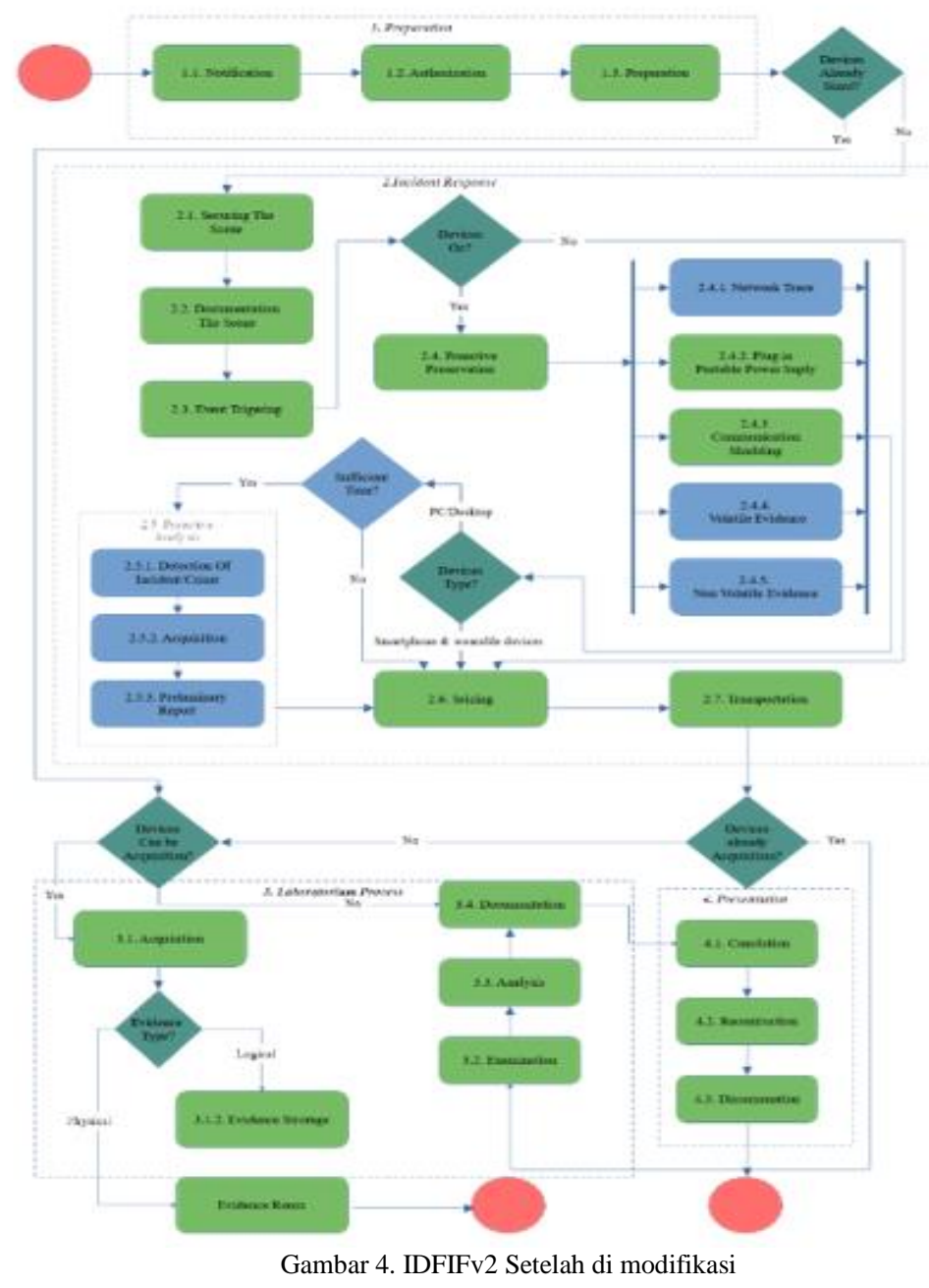

Dalam hal ini bisa di lihat pada gambar di atas tentang gambar kerangka kerja yang diperbaharui dan dimodifikasi, berikut gambar modifikasi pada tahapan Device Type. 


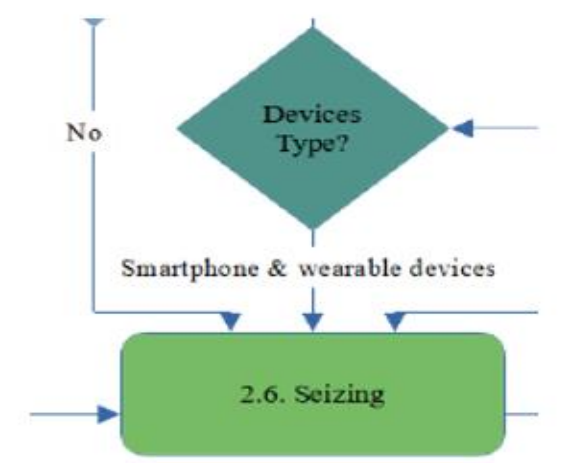

Gambar 5. Device Type IDFIFv2 Setelah Modifikasi

\section{5) Maintenance}

Tahapan ini adalah tahapan terakhhir dari SDLC yaitu perawatan kembali, dalam tahapan ini pemeliharaan dari kerangka kerja IDFIFv2 tetap dilakukan agar tetap dapat dipakai untuk analisis forensik dan juga dapat diperhatikan untuk mengikuti waktu yang terus berkembang. Sehingga kerangka kerja ini dapat menyesuaikan dengan penyelesaian investigasi forensik lebih lanjut. Dan sifat dari maintenance ini sendiri adalah ikut melakukan pemeliharaan dan perawatan secara khusus dengan mengikuti perkembangan dan melakukan perbandingan dari tiap investigasi dan analisis yang berlangsung pada smartwatch.

\section{A. Case Study}

Tahapan ini adalah tahapan penerapan IDFIFv2 dalam penanganan smartwatch dalam hal ini dibuat suatu skenario penyelesaian kasus investigasi forensik digital berdasarkan barang bukti yang ditemukan yaitu smartwatch. Skenario cerita ini berasal dari fiktif namun analisis forensik berdasarkan framework IDFIFv2 dilakukan secara nyata. Berikut gambar smartwatch dalam keadaan plug in power supply.

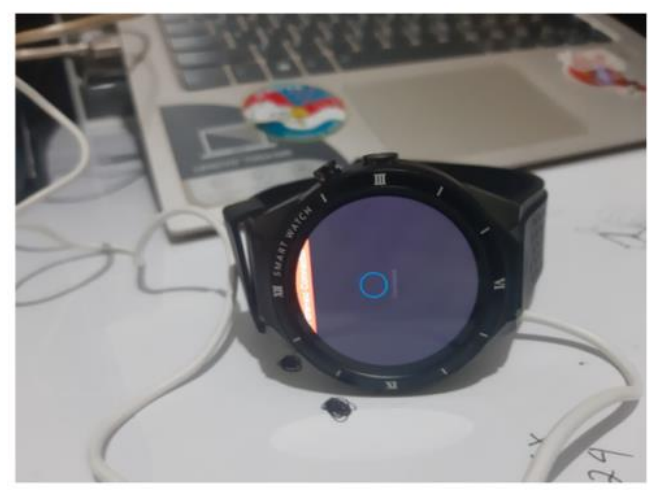

Gambar 6. Smartwatch dalam keadaan Power Supply

Dari studi kasus menggunakan smartwatch KW88 dan tools MobilEdit mendapatkan hasil interface sebagai berikut.

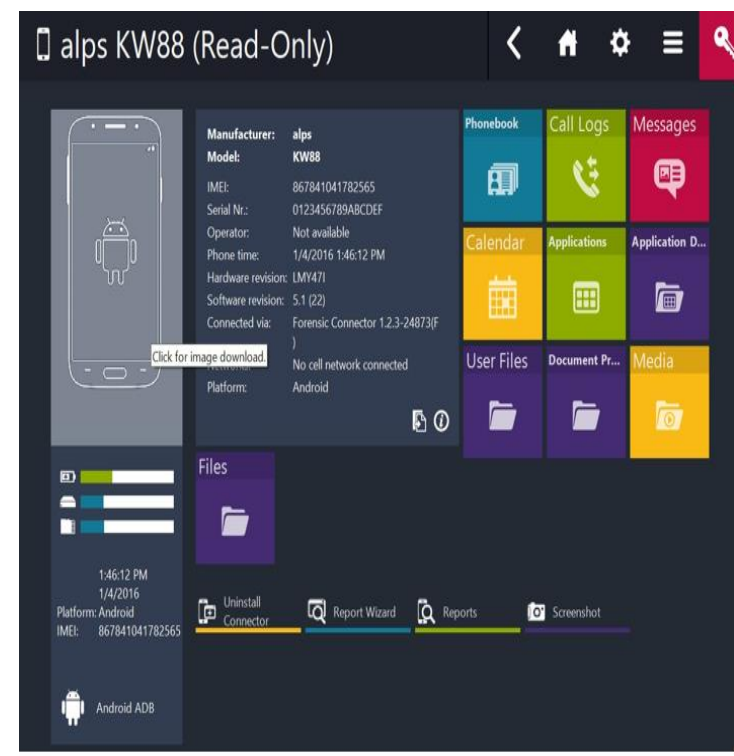

Gambar 7. Interface MobilEdit

hasil dari eksaminasi dan akuisisi mendapatkan data smartwatch berupa. Berikut tabel 5 memperlihatkan data yang bisa di akses.

Tabel 6. Data yang bisa di akses

\begin{tabular}{|c|c|}
\hline NO & Data \\
\hline 1 & Phonebook \\
\hline 2 & SMS \\
\hline 3 & Call Logs \\
\hline 4 & User Files \\
\hline 5 & Media \\
\hline 6 & Files \\
\hline
\end{tabular}

Dalam penerapan kerangka kerja atau framework, pada penyelesaian investigasi smartwatch tidak ditemukan adanya tahapan yang terbuang atau tidak terpakai, sehingga bisa dikatakan bahwa IDFIF v2 adalah framework yang cocok untuk smartwatch forensik. Berdasarkan tahapan sesuai studi kasus, tahapan yang digunakan bisa diterapkan secara maksimal terhadap smartwatch, mengingat prosedural dalam penanganan smartwatch dan smartphone sama. Sehingga bisa dijelaskan bahwa IDFIF v2 yang dimodifikasi dalam jangkauan device type bisa dipastikan tahapan yang terjadi tetap sama, bahkan dari segi perbandingan dari IDFIF v2 sebelumnya tidak ada perbedaan sehingga bisa di pastikan penerapan IDFIFv2 setelah di modifikasi untuk penanganan smartwatch dan smartphone di pastikan sama.

\section{Analisa Hasil}

Setiap kerangka kerja memiliki tahapan yang berbeda beda tergantung pada barang bukti yang di temukan dalam hal ini, bukti elektronik yang digunakan adalah smartwatch. IDFIF v2 merupakan model framework yang sudah mumpuni untuk melakukan penanganan bukti elektronik smartwatch dari tahapan awal sampai dengan akhir IDFIFv2 dapat menangani prosedur penanganan barang bukti smartwatch.

Kemudian berdasarkan hasil analisa masing-masing kerangka kerja ditemukan kelebihan dan kekurangan dalam penanganan smartwatch. Berdasarkan perbedaan kerangka kerja yang di bahas pada tabel 6 diperoleh kesimpulan IDFIFv2 yang telah di lakukan modifikasi seluruh 
tahapannya digunakan untuk penanganan barang bukti khususnya smartwatch berdasarkan hasil studi kasus yang telah di lakukan sebelumnya. Berikut tabel perbedaan kerangka kerja dalam penanganan smartwatch.

Tabel 7. Perbedaan kerangka kerja dalam penanganan smartwatch

\begin{tabular}{|c|c|c|c|}
\hline Nama & $\begin{array}{l}\text { Kerangka Kerja } \\
\text { (Framework) }\end{array}$ & Kelebihan & Kekurangan \\
\hline $\begin{array}{l}\text { (Odom et al., } \\
2019)\end{array}$ & $\begin{array}{l}\text { NIST (National } \\
\text { Institute of } \\
\text { Standards and } \\
\text { Technology) }\end{array}$ & $\begin{array}{l}\text { Mempunyai } \\
\text { tahapan yang } \\
\text { Dapat } \\
\text { mencakup } \\
\text { tahapan DFIF }\end{array}$ & $\begin{array}{l}\text { Penanganan } \\
\text { awal kejadian } \\
\text { barang bukti } \\
\text { ketika } \\
\text { ditemukan, } \\
\text { kemudian } \\
\text { seluruh barang } \\
\text { bukti di } \\
\text { kerjakan di } \\
\text { laboratorium }\end{array}$ \\
\hline $\begin{array}{l}\text { (Baggili et al., } \\
\text { 2015) }\end{array}$ & $\begin{array}{l}\text { NIST (National } \\
\text { Institute of } \\
\text { Standards and } \\
\text { Technology }\end{array}$ & $\begin{array}{l}\text { Tahapan yang } \\
\text { digunakan } \\
\text { mencakup } \\
\text { seluruh } \\
\text { tahapan DFIF }\end{array}$ & $\begin{array}{l}\text { Penanganan } \\
\text { barang bukti } \\
\text { langsung } \\
\text { dilakukan di } \\
\text { laboratorium } \\
\text { forensik } \\
\text { sehingga tidak } \\
\text { ada } \\
\text { penanganan } \\
\text { saat barang } \\
\text { bukti di } \\
\text { temukan. }\end{array}$ \\
\hline $\begin{array}{l}\text { (Putra et al., } \\
\text { n.d.) }\end{array}$ & $\begin{array}{l}\text { NIJ } \\
\text { Institute } \\
\text { Justice) }\end{array}$ & $\begin{array}{l}\text { Penanganan } \\
\text { setiap tahapan } \\
\text { sudah sesuai } \\
\text { dengan DFIF }\end{array}$ & $\begin{array}{l}\text { Tidak di } \\
\text { jelaskan } \\
\text { tentang } \\
\text { prosesi } \\
\text { dokumentasi } \\
\text { pada barang } \\
\text { bukti } \\
\text { elektronik }\end{array}$ \\
\hline $\begin{array}{l}\text { (Smartphones, } \\
\text { Rahman, \& } \\
\text { Riadi, 2019) }\end{array}$ & $\begin{array}{l}\text { IDFIFv2 } \\
\text { (Integrated } \\
\text { Digital Forensic } \\
\text { Imvestigation } \\
\text { Framework v2) }\end{array}$ & $\begin{array}{l}\text { Mempunyai } \\
\text { tahapan yang } \\
\text { fleksibel } \\
\text { dalam proses } \\
\text { investigasi } \\
\text { sampai dengan } \\
\text { penanganan } \\
\text { barang bukti }\end{array}$ & $\begin{array}{l}\text { Penanganan } \\
\text { hanya tertuju } \\
\text { pada } \\
\text { komputer dan } \\
\text { smartphone }\end{array}$ \\
\hline Lihawa & $\begin{array}{l}\text { IDFIFv2 } \\
\text { Modifikasi } \\
\text { (Integrated } \\
\text { Digital Forensic } \\
\text { Imvestigation } \\
\text { Framework v2) }\end{array}$ & $\begin{array}{l}\text { Memiliki } \\
\text { tahapan yang } \\
\text { fleksible } \\
\text { sehingga dapat } \\
\text { mencakup pc, } \\
\text { smartphone, } \\
\text { dan } \\
\text { smartwatch. }\end{array}$ & $\begin{array}{l}\text { Belum bisa } \\
\text { untuk } \\
\text { penanganan } \\
\text { cloud dan } \\
\text { network } \\
\text { forensik }\end{array}$ \\
\hline
\end{tabular}

\section{KESIMPULAN}

Penelitian dilakukan dengan barang bukti elektronik berupa smartwatch dengan menggunakan framework IDFIFv2 yang dimodifikasi untuk penanganan smartwatch dengan melakukan perbandingan berdasarkan penelitian sebelumnya. Dan dalam proses analisis ditemukan bahwa IDFIFv2 adalah salah satu kerangka kerja atau framework yang mumpuni untuk melakukan analisa forensik untuk smartwatch dari segi penanganan barang bukti sampai dengan presentasi, hanya saja IDFIFv2 sebelumnya dibuat untuk PC dan Smartphone jadi disini penulis melakukan modifikasi pada device type dengan menambahkan wearable devices, sehingga menjadi smartphone dan wearable devices. Selanjutnya dari hasil analisa bisa di dapatkan perbedaan kelebihan dan kekurangan dari masing-masing framework dalam penanganan smartwatch modifikasi dan IDFIFv2 adalah model kerangka kerja yang sesuai untuk penanganan barang bukti elektronik smartwatch.

Berdasarkan penelitian yang telah dilakukan, dapat disimpulkan bahwa IDFIFv2 adalah salah satu framework yang fleksibel yang dpat mencakup analisa forensik untuk smartwatch. Sehingga penyelesaian smartwatch forensik yang dilakukan dapat mencakup segala tahapan untuk analisa smartwatch forensik.

Penelitian kedepan yaitu adanya pengujian IDFIFv2 yang layak dicoba untuk wearable devices lainnya. juga mengharapkan adanya pengembangan IDFIFv2 untuk jenis forensik lainnya seperti cloud forensic dan network forensic.

\section{REFERENSI}

[1] Alexandra, J., Maria, E., \& Oktavia, T. (2019). Enrichment Program System to Enhance Student's Working Experience (Study Case: XYZ University). Proceeding - 2019 International Conference on ICT for Smart Society: Innovation and Transformation Toward Smart Region, ICISS 2019, 1-5. J. Clerk Maxwell, "A Treatise on Electricity and Magnetism," 3rd ed., vol. 2. Oxford: Clarendon, 1892, pp.68-73.

[2] Baggili, I., Oduru, J., Anthony, K., Breitinger, F., Mcgee, G., \& Haven, W. (2015). Watch what you wear: preliminary forensic analysis of smart watches. 4700. https://doi.org/10.1109/ARES.2015.39

[3] Databoks. (2019). Pengguna Smartphone di Indonesia 2016-2019. Retrieved December 9, 2011, from Katadata.co.id website: https://databoks.katadata.co.id/datapublish/2016/08/08/penggunasmartphone-di-indonesia-2016-2019.

[4] Ii, B. A. B., \& Teori, L. (2017). Eni Suryani. 9-27. Retrieved from http://elib.unikom.ac.id/files/disk1/642/jbptunikompp-gdl-enisuryan32065-8-unikom_e-i.pdf

[5] Kamila, A. R., \& Sutikno, S. (2017). Analysis of cause and effect relationship risk using fishbone diagram in SDLC SPASI v. 4.0 business process. 2016 International Conference on Information Technology Systems and Innovation, ICITSI 2016 - Proceedings. https://doi.org/10.1109/ICITSI.2016.7858186

[6] Khari, M., Vaishali, \& Kumar, P. (2016). Embedding security in Software Development Life Cycle (SDLC). Proceedings of the 10th INDIACom; 2016 3rd International Conference on Computing for Sustainable Global Development, INDIACom 2016, 2182-2186.

[7] Kheirkhahan, M., Nair, S., Davoudi, A., Rashidi, P., Wanigatunga, A. A., Corbett, D. B., ... Ranka, S. (2019). A smartwatch-based framework for real-time and online assessment and mobility monitoring. Journal of Biomedical Informatics, 89, 29-40. https://doi.org/10.1016/j.jbi.2018.11.003

[8] Odom, N. R., Lindmar, J. M., Hirt, J., \& Brunty, J. (2019). Forensic Inspection of Sensitive User Data and Artifacts from Smartwatch Wearable Devices. Journal of Forensic Sciences, 64(6), 1673-1686. https://doi.org/10.1111/1556-4029.14109

[9] Qazi, A., Shamim, A., \& Bano, H. (2013). Model driven architecture with encapsulated quality check and enhancement feature. $20133 \mathrm{rd}$ International Conference on Innovative Computing Technology, INTECH 2013, 537-540. https://doi.org/10.1109/INTECH.2013.6653634

[10]RI. (2008). Uu-2008-11 Informasi Dan Transaksi Elektronik. UndangUndang, 11, 1-18. Retrieved from papers3://publication/uuid/8C845E4E-CD67-4476-BB4F7123C56F0449

[11] Rhodes, D. L. (2012). The Systems Development Life Cycle (SDLC) as a Standard: Beyond the Documentation. SAS Global Forum 2012: Planning and Support, (194-2012), 1-5. Retrieved from http://support.sas.com/resources/papers/proceedings12/194-2012.pdf

[12] Ruuhwan, R., Riadi, I., \& Prayudi, Y. (2016). Penerapan Integrated Digital Forensic Investigation Framework v2 (IDFIF) pada Proses Investigasi Smartphone. Jurnal Edukasi Dan Penelitian Informatika (JEPIN), 2(1).

[13] Selamat, S. R., Yusof, R., \& Sahib, S. (2008). Mapping Process of Digital Forensic Investigation Framework. Journal of Computer 
Jurnal Teknologi Informasi dan Terapan (J-TIT) Vol. 8 No. 1 Juni 2020 ISSN: 2580-2291

Science, $\quad 8(10), \quad 163-169 . \quad$ Retrieved from http://paper.ijcsns.org/07 book/200810/20081025.pdf

[14] Smartphones, A., Rahman, R. D., \& Riadi, I. (2019). Framework Analysis of IDFIF V2 in WhatsApp Investigation Process on Framework Analysis of IDFIF V2 in WhatsApp Investigation Process on Android Smartphones. (October).

[15] Wahyudi, E., \& Prayudi, Y. (2016). Digital forensics framework manajemen investigasi kriminal. (June). 